\title{
Isotopic Studies on Collagen Degradation and the Urine Excretion of Hydroxyproline *
}

\author{
Darwin J. Prockop \\ (From the Departments of Medicine and Biochemistry, University of Pennsylvania, and the \\ Philadelphia General Hospital, Philadelphia, Pa.)
}

Although marked changes in collagen can be observed in a number of clinical conditions, initial studies of the metabolic turnover of collagen suggested that this protein was metabolically more stable than other body proteins and that perhaps it was metabolically inert. After injecting glycine- $\mathrm{C}^{14}$ into rats, Neuberger, Slack (2), and Perrone (3) found that much less radioactivity was incorporated into collagen than into liver proteins. In addition, they found that the small amount of glycine- $\mathrm{C}^{14}$ that did enter collagen disappeared with a half-life of over six weeks in young rats and longer in old rats. Subsequently, a number of investigators $(4,5)$ demonstrated rapid turnover rates in the small amount of "soluble" collagen which can be extracted from most tissues and is a precursor of insoluble collagen. Significant degradation of collagen, however, was not evident in studies performed directly on normal tissues. Recently, Lindstedt and Prockop (6) attempted to study the metabolic turnover of collagen by injecting proline- $\mathrm{C}^{14}$ into rats and then following the specific activity of urine hydroxyproline-C ${ }^{14}$. Since nearly all the hydroxyproline in vertebrates is found in collagen, and since the only source of this amino acid appears to be the hydroxylation of "bound" proline in situ $(7,8)$, the decay of urine hydroxyproline- $\mathrm{C}^{14}$ was assumed to reflect the degradation in vivo of collagen or its immediate precursors. The results suggested that although most of body collagen is metabolically stable, there are forms that are both synthesized and degraded rapidly under normal conditions.

* Submitted for publication August 9, 1963 ; accepted November 14, 1963.

A preliminary report of this work has been presented (1). The studies were supported in part by U. S. Public Health Service grants A-5978 and AM-K3-14,916 from the National Institute of Arthritis and Metabolic Diseases.
In the present study an attempt was made to identify further the metabolically active forms of collagen and to verify previous suggestions that urine hydroxyproline originates from the degradation of body collagen.

\section{Methods}

Albino male Sprague-Dawley rats 3 to 4 weeks old were used in the experiments. The rats were maintained on a diet ${ }^{1}$ adequate for normal growth but containing no hydroxyproline. They were placed in metabolic cages, and after acclimatization for 4 to 5 days, they were injected with $25 \mu \mathrm{c}$ of uniformly labeled proline- $\mathrm{C}^{\mathbf{1 4}}, 10 \mu \mathrm{c}$ per mole, ${ }^{2}$ in $1 \mathrm{ml}$ of $0.9 \% \mathrm{NaCl}$. The proline- $\mathrm{C}^{14}$ had been previously chromatographed with carrier hydroxyproline and found to contain less than $0.01 \%$ hydroxyproline- $\mathrm{C}^{14}(6)$. Urine was collected under toluene at 24-hour intervals except that with two rats the collections were for 15 hours only.

The rats were decapitated, the hair was shaved off, and the skin was taken for the extraction of soluble and insoluble collagen. The remainder of the animal, here referred to as "carcass," was prepared separately for the extraction of soluble and insoluble collagen. In preliminary experiments a Waring blendor and a Lourdes homogenizer were employed to homogenize the samples, but subsequently a meat grinder cooled with dry ice (9) was used. The homogenates were immediately placed in 5 vol of $0.9 \% \mathrm{NaCl}$ and extracted on a rotatory shaker at $4^{\circ} \mathrm{C}$ for 24 hours. The samples were then centrifuged at $20,000 \times g$ for 1 hour, and the supernatant solutions were taken for assay of soluble collagen hydroxyproline (infra). Fats were removed from the residue by extracting twice with 5 vol of absolute ethanol and then with 5 vol of boiling ethanol:ether $(1: 2)$. The extracts were discarded, and the insoluble collagen in the residue was solubilized as gelatin by adding $20 \mathrm{vol}$ of water and autoclaving at $124^{\circ}$ for 1 hour. The remaining insoluble residue was removed from the gelatin solution by filtering with a Buchner funnel.

The soluble collagen ${ }^{3}$ extract was dialyzed against 20

1 Nutritional Biochemical Corp., Cleveland, Ohio.

2 Nuclear-Chicago Corp., Des Plaines, Ill.

3 The term "soluble collagen" is used here to refer to the nondialyzable, hydroxyproline-containing materials extracted with $0.9 \% \mathrm{NaCl}$ under the conditions described. 
vol of distilled water at $4^{\circ} \mathrm{C}$ overnight, and then it was evaporated to dryness with a rotatory evaporator in vacuo at $100^{\circ}$. The samples were hydrolyzed by adding ten times the original tissue volume of $6 \mathrm{~N} \mathrm{HCl}$ and autoclaving at $124^{\circ}$ for 15 hours. The hydrolysates were evaporated to dryness, adjusted to $\mathrm{pH} 7$ with $\mathrm{NaOH}$, and chromatographed on a cation exchange resin column 4 developed with $1.5 \mathrm{~N} \mathrm{HCl}$ (6). The eluted fractions were assayed for hydroxyproline by procedure II of Prockop and Udenfriend (10), and the tubes containing hydroxyproline were pooled for quantitative assay (10) and for determination of hydroxyproline- $\mathrm{C}^{\mathbf{1 4}}$ specific activity (11). In a number of experiments the hydroxyproline- $\mathrm{C}^{\mathbf{1 4}}$ fractions isolated from the column were treated with nitrous acid (12) to destroy nonpyrrolidine amino acids. The samples were then passed through the same type of cation exchange resin column a second time, and they were eluted with $1.5 \mathrm{~N} \mathrm{NH}_{4} \mathrm{OH}$. The assays for hydroxyproline- $\mathrm{C}^{\mathbf{1 4}}$ specific activity were then repeated.

Fractions of the gelatinized insoluble collagen 5 were hydrolyzed with equal volumes of concentrated $\mathrm{HCl}$ at $124^{\circ}$ for 15 hours, evaporated to dryness, and assayed directly for hydroxyproline content (10) and for hydroxyproline- $C^{\mathbf{1 4}}$ specific activity (11). Hydroxyproline assays on urine samples were performed as described previously (6). Because samples collected during the first 7 days after the isotope administration contained large amounts of proline- $\mathrm{C}^{14}$, the hydroxyproline in these samples was separated from proline on a cation exchange resin column before assay (6).

Recoveries based on the addition of hydroxyproline internal standards were 92 to $102 \%$ in the quantitative assays by procedure II(10). In the assays of hydroxyproline- $C^{14}$ specific activity, comparison of the amounts of isolated pyrrole with the results of the quantitative assay indicated an over-all yield of 50 to $85 \%$ in most instances, but occasionally yields as low as $25 \%$ were encountered (vide infra). By repeating the assays with different amounts of oxidant $(10,11)$, the yields obtained with samples that initially gave low values could be increased to 70 to $85 \%$. Observed counts per minute were converted to disintegrations per minute by reference to benzoic acid- $\mathrm{C}^{14}$ standards. ${ }^{6}$

\section{Results}

Yields of soluble and insoluble collagen. A number of preliminary studies were performed to select an adequate technique for isolating signifi-

4 AG 50W-X8, hydrogen form, California Biochemical Corp., Los Angeles, Calif.

5 The insoluble collagen isolated probably included collagen from more soluble fractions, but since the amount of soluble collagen in normal tissues is small compared to the amount of insoluble collagen, the presence of a small fraction with a high specific activity would not have been detected.

6 Obtained from the National Bureau of Standards. cant quantities of soluble collagen hydroxyproline from both skin and carcass. Milligram quantities were readily obtained when high speed homogenizers were employed, but a uniform suspension was not obtained from skin or carcass samples even with prolonged homogenization, and the heat generated during the procedure introduced the possibility of contaminating the soluble collagen with gelatinized insoluble collagen. Although yields were considerably less, particularly with carcass samples, the meat grinder technique (9) was finally employed for all the experiments reported here, because the danger of contamination with insoluble collagen was minimal. After extraction of the homogenate with $0.9 \% \mathrm{NaCl}$ at $4^{\circ} \mathrm{C}$, an attempt was made to precipitate the soluble collagen with salt (13). Control experiments, however, indicated that only 50 to $80 \%$ of the nondialyzable hydroxyproline in the carcass extracts was precipitated at $4^{\circ} \mathrm{C}$ with a final $\mathrm{NaCl}$ concentration of $20 \%$. Accordingly, no attempt was made to purify the soluble collagen, and total nondialyzable hydroxyproline in the cold saline extracts was assayed as soluble collagen ${ }^{3}$ hydroxyproline. Over-all yields of hydroxyproline isolated from the soluble collagen fractions varied from 0.5 to $7.5 \mathrm{mg}$ (Table I).

Yields of insoluble collagen hydroxyproline varied from $142 \mathrm{mg}$ in $50 \mathrm{-g}$ rats to as much as $1,290 \mathrm{mg}$ in $200 \mathrm{~g}$ rats (Table I). Total body content of collagen, calculated on the basis of a collagen hydroxyproline content of $13 \%$, was found to vary from 2.0 to $4.5 \%$ of the total body weight. The proportionate yield of collagen hydroxyproline appeared to be greater with larger animals, but considerable variation was encountered. $^{7}$

Assay of hydroxyproline-C $C^{14}$ specific activity. The procedure employed for the assay of hydroxyproline- $\mathrm{C}^{14}$ specific activity (11) involves the oxidation and decarboxylation of hydroxypro-

7 The variations in the yields of insoluble collagen hydroxyproline may reflect individual differences in the nutritional status of the animals (6), but the relatively mild homogenization procedure may also have contributed to low yields in some cases. Since the primary purpose of these experiments was to measure the specific activity of collagen hydroxyproline, and since the variations in yield were unlikely to affect the observed specific activities, no systematic attempt was made to investigate this point. 
line to pyrrole. The pyrrole is extracted into toluene, and a fraction of the toluene solution can be employed for a colorimetric assay while the remainder of the toluene solution is used for radioactive assay in a liquid scintillation counter. The initial oxidation product obtained from hydroxyproline is probably pyrrole-2-carboxylic acid (10), and because this intermediate is not extracted by toluene under the conditions employed, interfering radioactive materials are removed by toluene extractions after the oxidation but before the sample is heated at $100^{\circ}$ for 25 minutes to decarboxylate the pyrrole-2-carboxylic acid to pyrrole. Because heating the sample probably does not increase the amount of radioactivity that can be extracted into toluene from other oxidation products, the last toluene extraction obtained before the sample is heated can be employed as an indication of interference by radioactive materials other than hydroxyproline and as a "blank" for the assay. In employing the assay, it is important to note that although the colorimetric assay for pyrrole in the final toluene solution is highly sensitive and specific (10), the observed radioactivity may be spuriously elevated if excessive amounts of labeled compounds such as proline are present (11). Accordingly, the assay can give erroneously high values for specific activity if the samples contain large amounts of radioactivity in materials other than hydroxyproline, but erroneously low values for specific activity are unlikely.
In the assays of the specific activity of urine hydroxyproline, 100 to $400 \mu \mathrm{g}$ equivalents or 0.8 to $3 \mu$ moles of pyrrole was readily isolated from individual samples, although occasionally assays had to be repeated with different amounts of oxidant (11) to improve the yields. Similarly, little difficulty was encountered in assaying the specific activity of hydroxyproline of the insoluble collagen in skin or carcass samples, and from 100 to 2,000 $\mu \mathrm{g}$ equivalents of pyrrole was obtained. "Blanks" for these assays were generally less than three times the background of the liquid scintillation counter (11 to $14 \mathrm{cpm}$ ), and the observed radioactivity in the pyrrole was more than ten times the level in the blanks. Repeated assays on the same samples agreed within $5 \%$.

Initially, considerable difficulty was encountered in assaying the specific activity of hydroxyproline from the soluble collagen fractions, particularly with the carcass soluble collagen. Because of the large amounts of materials other than hydroxyproline in the samples, direct assay on the hydrolysates gave low yields of pyrrole, high radioactive "blanks," and considerably higher values for specific activity than were obtained after partial isolation of the hydroxyproline. Assays on the hydroxyproline fractions obtained after column chromatography were more satisfactory. Adequate yields of pyrrole were obtained more consistently after the column fractions were treated with nitrous acid, but there was no significant

TABLE I

Yields of hydroxyproline from salt soluble and insoluble collagen fractions*

\begin{tabular}{|c|c|c|c|c|c|c|}
\hline \multirow[b]{2}{*}{ Rat } & \multirow[b]{2}{*}{ Wt } & \multicolumn{2}{|c|}{ Soluble collagen hydroxyproline } & \multicolumn{2}{|c|}{ Insoluble collagen hydroxyproline } & \multirow{2}{*}{$\begin{array}{l}\text { Collagen a } \\
\text { \% body w }\end{array}$} \\
\hline & & Skin & Carcass & Skin & Carcass & \\
\hline $\begin{array}{r}\text { I } \\
\text { II } \\
\text { III }\end{array}$ & $\begin{array}{l}g \\
54 \\
50 \\
56\end{array}$ & $\begin{array}{l}m g \\
.60 \\
.78 \\
.46\end{array}$ & $\begin{array}{c}m g \\
1.74 \\
.77\end{array}$ & $\begin{array}{c}m g \\
42 \\
44 \\
33\end{array}$ & $\begin{array}{c}m g \\
102 \\
98 \\
123\end{array}$ & $\begin{array}{c}\% \\
2.0 \\
2.2 \\
2.1\end{array}$ \\
\hline $\begin{array}{r}\text { IV } \\
\text { V } \\
\text { VI } \\
\text { VII }\end{array}$ & $\begin{array}{l}76 \\
85 \\
72 \\
82\end{array}$ & $\begin{array}{r}.55 \\
1.70 \\
.97\end{array}$ & $\begin{array}{r}1.44 \\
.93 \\
1.10\end{array}$ & $\begin{array}{l}94 \\
77 \\
92 \\
90\end{array}$ & $\begin{array}{l}320 \\
324 \\
240 \\
192\end{array}$ & $\begin{array}{l}4.3 \\
3.7 \\
3.5 \\
2.6\end{array}$ \\
\hline 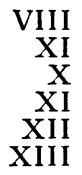 & $\begin{array}{l}223 \\
220 \\
207 \\
185 \\
219 \\
244\end{array}$ & $\begin{array}{l}1.30 \\
2.14 \\
2.54 \\
1.23\end{array}$ & $\begin{array}{l}7.50 \\
3.76\end{array}$ & $\begin{array}{l}603 \\
558 \\
144 \\
248 \\
158 \\
240\end{array}$ & $\begin{array}{l}630 \\
730 \\
499 \\
608 \\
986 \\
875\end{array}$ & $\begin{array}{l}4.1 \\
4.5 \\
2.3 \\
3.6 \\
4.0 \\
3.5\end{array}$ \\
\hline
\end{tabular}

* With the samples from rats I, II, VI, VII, VIII, and IX, the yields of hydroxyproline from soluble collagen reflect the amount isolated after both column chromatography and treatment with nitrous acid. 
TABLE II

Specific activity of urine hydroxyproline after intraperitoneal injection of proline-C $C^{14}$ in rats

\begin{tabular}{ccc}
\hline \hline Time after injection & No. of rats & $\begin{array}{c}\text { SA of hydroxyproline in } \\
\text { 15-hour or 24-hour sample }\end{array}$ \\
\hline & & $d p m / \mu g$ \\
15 hours & 2 & 62,55 \\
24 hours & 8 & $38 \pm 7.09$ SD \\
6 days & 8 & $9.1 \pm 1.06$ SD \\
28 days & 6 & $1.3 \pm 0.27$ SD \\
\hline
\end{tabular}

difference in the values obtained for specific activity. From 70 to $180 \mu \mathrm{g}$ equivalents of pyrrole was isolated in the final assays on the soluble collagen fractions from rats I, II, III, VI, and VII, and from 640 to $1,000 \mu \mathrm{g}$ equivalents was isolated from rats VIII and IX. With each of these samples the levels of radioactivity in the blanks were less than $50 \mathrm{cpm}$, and the radioactivity in the toluene extract containing the pyrrole was more than ten times the level in the blanks. Because of high blank values or low yields of radioactive pyrrole, the assays were less satisfactory with the samples obtained from rats $\mathrm{V}$, $\mathrm{X}$, and XI, and the values quoted for the specific activity of soluble collagen in these animals should be regarded as maximal estimates only.

Specific activity of urine hydroxyproline-C $C^{\mathbf{1 4}}$. Rats were injected with proline- $\mathrm{C}^{14}$, and the specific activity of urine hydroxyproline- $\mathrm{C}^{14}$ was determined in 15- or 24-hour samples collected after 15 hours, 24 hours, six days, and 28 days (Table II). Peak labeling of the urine hydroxyproline- $\mathrm{C}^{14}$ probably occurred in less than 15 hours, since the specific activities of samples collected over the first 15 hours were greater than the values for samples collected over the first 24 hours. As reported previously, the specific activity of urine hydroxyproline decreased rapidly during the first week after the proline- $\mathrm{C}^{\mathbf{1 4}}$ administration, and a further decrease was observed after the first week (6). Little additional decrease occurred after 3 weeks, and the specific activity of successive 24-hour urine samples collected from the same rats between days 26 and 28 varied by less than $0.1 \mathrm{dpm}$ per $\mu \mathrm{g}$.

The specific activity of the urine hydroxyproline was significantly less when the subcutaneous rather than the intraperitoneal route of administration was employed (see rat III in Ta- ble III), but when the same route of administration was employed, the values were comparable to those reported previously (6).

Comparison of collagen and urine hydroxyproline- $C^{14}$. Because of variations in the degree of collagen labeling in individual animals (vide infra), the specific activity of urine hydroxyproline at various times was compared only with the specific activity of the collagen hydroxyproline isolated from the same animal (Table III). In the two rats killed 15 hours after the $C^{14}$ injection, the specific activity of the hydroxyproline in soluble collagen of the skin and the carcass was about twice the specific activity of the hydroxyproline in the insoluble collagen fractions. In both of these animals the specific activity of urine hydroxyproline was about three times the specific activity of the hydroxyproline in insoluble collagen and one and one-half times the specific activity of the hydroxyproline in the soluble collagen. In the one animal examined after 24 hours, the specific activity of hydroxyproline in the insoluble collagen and in urine was considerably less than in the animals killed after 15 hours, probably because a subcutaneous rather than intraperitoneal injection was employed.

TABLE III

Specific activity of collagen and urine hydroxyproline after injection of proline-C $C^{14}$

\begin{tabular}{|c|c|c|c|c|c|c|}
\hline \multirow[b]{2}{*}{ Rat } & \multirow[b]{2}{*}{ Time } & \multicolumn{2}{|c|}{ Soluble collagen } & \multicolumn{2}{|c|}{ Insoluble collagen* } & \multirow[b]{2}{*}{ Urine } \\
\hline & & Skin & Carcass & Skin & Carcass & \\
\hline & & $d p m / \mu g$ & $d p m / \mu g$ & $\underset{\mu g}{d p m}$ & $\underset{\mu g}{d p m /}$ & $\underset{\mu g}{d p m}$ \\
\hline I & 15 hours & 46.0 & 40.0 & 23.0 & 23.0 & 64.0 \\
\hline II & 15 hours & 44.0 & 44.0 & 20.0 & 22.0 & 55.0 \\
\hline III $\dagger$ & 24 hours & 36.0 & & 9.1 & 8.0 & 22.0 \\
\hline IV & 6 days & & & 7.0 & 7.6 & 9.0 \\
\hline $\mathrm{V}$ & 6 days & $<2.0$ & $<6.9$ & 5.1 & 5.8 & 9.1 \\
\hline VI & 7 days & 1.4 & 5.7 & 6.3 & 7.8 & 8.1 \\
\hline VII & 7 days & 1.8 & 6.4 & 7.4 & 8.7 & 8.0 \\
\hline VIII & 28 days & 0.31 & 0.29 & 1.8 & 1.6 & 1.1 \\
\hline & 28 days & 0.29 & 0.30 & 1.8 & 2.9 & 1.7 \\
\hline & 28 days & $<0.8$ & & 2.1 & 2.6 & 1.4 \\
\hline XI & 31 days & $<0.5$ & & 1.8 & 2.0 & \\
\hline XII & 28 days & & & 1.6 & 2.0 & 1.0 \\
\hline XIII & 28 days & & & 1.9 & 2.1 & 1.4 \\
\hline
\end{tabular}

* Values for the specific activity of insoluble collagen hydroxyproline are not corrected for the growth and the increases in total body collagen that occurred during the experiment (see Table I).

$\dagger$ Proline-C ${ }^{14}$ was administered by subcutaneous rather than intraperitoneal injection. 
In the two rats examined 7 days after the proline-C $\mathrm{C}^{14}$ injection, the specific activity of hydroxyproline in skin soluble collagen was about $25 \%$, and the carcass soluble collagen was 73 to $90 \%$ of the specific activity of the hydroxyproline in the insoluble collagen fractions. The specific activity of the soluble collagen from the carcass fraction was over three times the specific activity of the hydroxyproline from the skin soluble collagen, although these fractions had comparable values in animals examined within 24 hours. The specific activity of the urine hydroxyproline was approximately equal to that of the hydroxyproline in the insoluble collagen, and four to five times greater than that of the hydroxyproline in the skin soluble collagen fraction. Comparable values for the specific activity of hydroxyproline from insoluble collagen and urine were found in two rats examined after 6 days, and in rat $\mathrm{V}$ the observed specific activities of hydroxyproline in the soluble collagen fractions were similar, even though the level of confidence in these values is less than for the values obtained for rats VI and VII.

In the two rats in which all four collagen fractions were examined after 28 days, the specific activities of the hydroxyproline in the soluble collagen fractions were less than one-fifth of that in the insoluble collagen, and they were one-third to one-fifth the specific activity of the urine hydroxyproline. In rats $\mathrm{X}$ and $\mathrm{XI}$, the specific activities of the skin soluble collagen were somewhat higher, but the results obtained in the assays were not entirely satisfactory, and the specific activity of the soluble collagen was still considerably less than the specific activity of either the insoluble collagen or urine hydroxyproline in these animals. In the six rats killed after 28 to 31 days, the specific activity of the urine hydroxyproline was 56 to $74 \%$ of the mean specific activity of the hydroxyproline in the insoluble collagen fractions.

When rats $\mathrm{X}$ and $\mathrm{XI}$ were killed, a femur from each was removed and assayed separately for insoluble collagen hydroxyproline. The specific activities of hydroxyproline were 2.6 and 1.9 , respectively, or within $10 \%$ of the value obtained for the hydroxyproline in the carcass insoluble collagen from these animals.

\section{Discussion}

Several problems are encountered in attempting to measure the metabolic turnover of collagen with the same isotopic techniques that have been used for other body constituents. The bulk of body collagen is slowly metabolized, and it is poorly labeled by the single, acute administration of isotope usually employed (14). As a result, significant changes in the label can be obscured by variations in the amounts of isotope initially incorporated by individual animals. In addition, the collagen of the body or even of a single tissue cannot be regarded as a single homogeneous pool, since most tissues contain a variety of soluble collagens having different turnover rates (15). The technique of administering labeled proline and following the specific activity of urine hydroxyproline offers several advantages over earlier methods of studying body collagen. All the measurements can be made in a single animal, and apparently the catabolic products of collagen degradation can be examined selectively. The technique involves the assumption that the endogenous hydroxyproline in urine, most of which is in a peptide-bound form (16), originates from the degradation of collagen. Earlier evidence in favor of this assumption has been summarized $(16,17)$ and is supported by recent reports $(18,19)$ indicating that the amino acid composition of the hydroxyproline peptides excreted in urine is consistent with the amino acid composition of collagen.

Initial studies (6) on urine hydroxyproline- $\mathrm{C}^{14}$ demonstrated at least three separate components in the excretion curves, thus indicating the presence of at least three different hydroxyproline pools with half-lives of about 1 day, 5 days, and 50 to 100 days. Comparison of the data with previously published observations on the metabolic turnover of various collagen fractions suggested that the first two hydroxyproline pools probably represented forms of soluble collagen, and that the third pool was probably identical with insoluble collagen. In general, the results obtained here support these conclusions, since 15 hours after administration of the proline- $\mathrm{C}^{14}$ the specific activity of urine hydroxyproline was comparable to that of soluble collagen hydroxyproline, and 28 days after the isotope was adminis- 
tered, the specific activity of urine hydroxyproline was comparable to that of insoluble collagen hydroxyproline. The correlation between urine and collagen specific activities was not exact, but notice must be taken of the fact that in animals killed within 1 week, significant changes in collagen specific activity occurred during the interval required for an adequate urine collection. Jackson and Bentley (15) found that the specific activity of collagen soluble in cold $0.14 \mathrm{M} \mathrm{NaCl}$ reached a maximum within 8 hours, and then it decreased rapidly. Accordingly, the specific activity of soluble collagen observed at 15 hours is probably less than the average value for this fraction during the 15 hours in which the first urine sample was collected. The evidence that peak labeling of urine hydroxyproline occurred in less than 15 hours is consistent with this conclusion. The small discrepancies between the urine and collagen hydroxyproline- $\mathrm{C}^{14}$ in rats killed after 6 or 7 days may also be explained by the possibility that significant decreases occurred in the specific activities of collagen fractions during the time required to collect the urine samples. However, the urine hydroxyproline- $\mathrm{C}^{14}$ may possibly originate from a collagen fraction which is an intermediate between soluble and insoluble collagen, and 1 to 7 days after the administration of the proline- $\mathrm{C}^{14}$ this intermediate fraction may have a higher specific activity than either of the two fractions isolated here. $^{5}$

The results obtained in animals killed after 4 weeks are of interest in several special respects. The urine hydroxyproline- $\mathrm{C}^{14}$ excreted at this time could not have originated from the degradation of soluble collagen, since the specific activity of the urine hydroxyproline in these animals was significantly greater than the specific activity of the soluble collagen. Similarly, precursors of soluble collagen were unlikely to have contributed significantly to urine hydroxyproline- $\mathrm{C}^{14}$, since the specific activity of any precursors can be assumed to be less than that of the soluble collagen. The specific activity of the insoluble collagen, however, was greater than that of the urine hydroxyproline, and therefore the results support the previous suggestion (6) that significant amounts of urine hydroxyproline peptides originate from the degradation of insoluble collagen.

The low specific activity of the soluble collagen fraction after 4 weeks indicates that little further labeling of collagen was occurring at this time. The specific activity of the soluble collagen isolated can probably be assumed to reflect the specific activity of all hydroxyproline-containing precursors of insoluble collagen, and therefore the fractional contribution of insoluble collagen to urine hydroxyproline can be estimated from the formula,

$$
f_{1} x_{1}+f_{2} x_{2}=x_{3},
$$

where $f_{1}$ is the fractional contribution of hydroxyproline pools other than insoluble collagen to urine hydroxyproline- $\mathrm{C}^{14}, f_{2}$ is the fractional contribution of insoluble collagen, and $x_{1}, x_{2}$, and $x_{3}$ are the specific activities of the hydroxyproline- $\mathrm{C}^{14}$ in body pools other than insoluble collagen, in insoluble collagen, and in urine, respectively. By definition,

$$
f_{1}+f_{2}=1.00
$$

and when appropriate values for $x_{1}, x_{2}$, and $x_{3}$ are substituted, Equations 1 and 2 indicate that $57 \%$ of the hydroxyproline- $\mathrm{C}^{14}$ excreted during day 28 by rat VIII was derived from insoluble collagen. Similarly, $70 \%$ of the hydroxyproline$\mathrm{C}^{14}$ excreted by rat IX during day 28 was derived from insoluble collagen.

The results do not indicate whether insoluble collagen is directly degraded to urine peptides or whether insoluble collagen is first converted to more soluble forms of collagen before degradation (15). Also, there is no indication whether the insoluble collagen in all tissues and organs is degraded to urine hydroxyproline at the same rate. Most of the hydroxyproline excreted may originate from a single tissue such as bone, but in two rats killed after four weeks, the specific activities of the insoluble collagen from skin, carcass, and bone were similar. Therefore, under the conditions studied here urine hydroxyproline- $\mathrm{C}^{14}$ probably originated from the degradation of the insoluble collagen of a number of different tissues, and the metabolic turnover of body collagen as a whole can be summarized by the general scheme shown in Figure 1.

Recently, a number of attempts have been made to use the amount of hydroxyproline excreted endogenously as an index of collagen metabolism in various clinical and experimental disorders. 


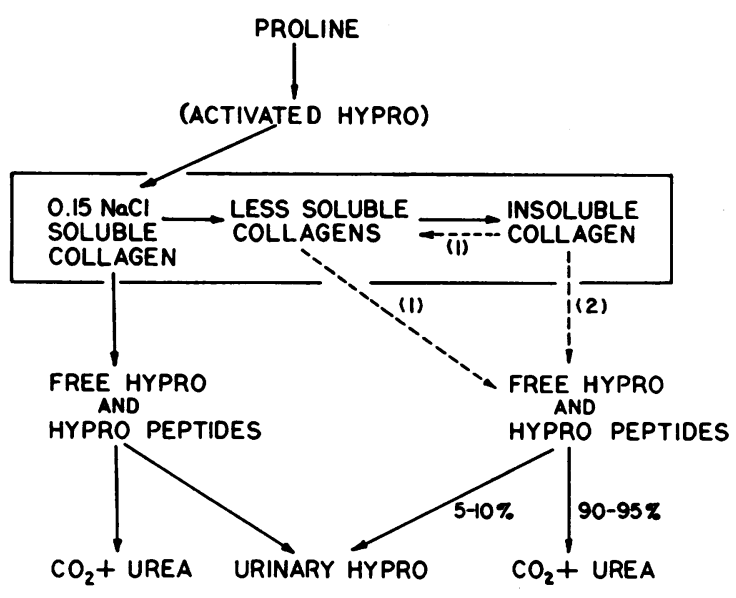

Fig. 1. MOdel SCHEME SUggested FOR THE DEGRAdATION OF SOLLBLE AND INSOLUBLE COLLAGEN TO URINE HYDROXYPROLINE (HYPRO) PEPTIDES. Because peak labeling of hydroxyproline in soluble collagen and urine occurs soon after administration of proline- $\mathrm{C}^{\mathbf{1 4}}$, soluble collagen is probably degraded directly to yield urine hydroxyproline. It is not clear, however, whether insoluble collagen is converted to more soluble forms before final degradation (reaction 1), or whether it is directly degraded to urine hydroxyproline (reaction 2 ).

Increased rates of hydroxyproline excretion have been found in several conditions in which increased rates of collagen degradation or collagen turnover could be expected, such as growth periods in children (16) and animals (6), Marfan's syndrome (20), experimental lathyrism (21), acromegaly (22), Paget's disease (23), hyperthyroidism (24), and active phases of scleroderma (25). Conversely, decreased rates of hydroxyproline excretion have been found in conditions in which decreased collagen degradation or turnover could be anticipated, such as old animals (6), pituitary dwarfism (22), hypothyroidism (24), and scurvy (21). In a few instances, however, changes in hydroxyproline excretion have not been observed in circumstances where rapid degradation of collagen is known to occur. For example, increased excretion of hydroxyproline was not observed during postpartum involution of the uterus in pregnant rats (26) or during resorption of carrageenan granulomas (21), even though considerable amounts of collagen disappeared from the tissues. The sensitivity with which hydroxyproline excretion reflects changes in collagen metabolism depends in part on the completeness with which the hydroxyproline pep- tides released during collagen degradation are excreted in urine rather than being degraded further to other amino acids, carbon dioxide, and urea (Figure 1). No direct measurements are available on the relative fraction of hydroxyproline excreted during collagen degradation, but an approximation can be made from the available data. The half-life of insoluble collagen in young adult rats is 50 to 100 days $(2,3,6)$, and if the highest yields in Table $I$ are accepted as the most accurate, ${ }^{6}$ the total body content of insoluble collagen hydroxyproline in these rats was about 1.2 g. If all the hydroxyproline from the breakdown of insoluble collagen were excreted, the rats should excrete 5 to $12 \mathrm{mg}$ of hydroxyproline per day. Since the actual excretion rates observed were about $0.9 \mathrm{mg}$ per day (6), and since only about two-thirds of this amount originated from insoluble collagen (supra), the data suggest that only 5 to $10 \%$ of the hydroxyproline released by the degradation of insoluble collagen was excreted under normal conditions. Although this estimate is only approximate, and although it applies only to insoluble collagen, it probably explains the failure to observe changes in hydroxyproline excretion in postpartum rats or in animals with carrageenan granulomas. Also, it suggests that relatively large changes in the rate of collagen degradation are required to produce significant changes in the amount of hydroxyproline excreted in urine.

\section{Summary}

Proline- $\mathrm{C}^{14}$ was injected into young rats, and the specific activity of the hydroxyproline- $\mathrm{C}^{14}$ excreted in urine was compared with the specific activity of hydroxyproline- $\mathrm{C}^{14}$ in soluble and insoluble collagen. Fifteen hours after the proline- $\mathrm{C}^{14}$ injection, the specific activity of urine hydroxyproline- $\mathrm{C}^{14}$ was comparable to specific activity of hydroxyproline- $\mathrm{C}^{14}$ in soluble collagen. Four weeks after administration of the isotope, the specific activity of urine hydroxyproline was considerably greater than the specific activity of hydroxyproline in soluble collagen but somewhat less than the specific activity of hydroxyproline in insoluble collagen. The results suggest that the endogenous hydroxyproline peptides excreted in urine originate from the degradation of both soluble and insoluble collagen. An estimate of the 
fractional recovery of insoluble collagen hydroxyproline as urine hydroxyproline suggests that relatively large changes in the rate of collagen degradation are required to produce significant changes in the amount of imino acid excreted in urine.

\section{References}

1. Prockop, D. J. Collagen degradation and urinary hydroxyproline. Fed. Proc. 1962, 21, 169.

2. Neuberger, A., and H. G. B. Slack. The metabolism of collagen from liver, bone, skin and tendon in the normal rat. Biochem. J. 1953, 53, 47.

3. Neuberger, A., J. C. Perrone, and H. G. B. Slack. The relative metabolic inertia of tendon collagen in the rat. Biochem. J. 1951, 49, 199.

4. Harkness, R. D., A. M. Marko, H. M. Muir, and A. Neuberger. The metabolism of collagen and other proteins of the skin of rabbits. Biochem. J. 1954, 56, 558.

5. Jackson, D. S. Connective tissue growth stimulated by carrageenin. I. The formation and removal of collagen. Biochem. J. 1957, 65, 277.

6. Lindstedt, S., and D. J. Prockop. Isotopic studies on urinary hydroxyproline as evidence for rapidly catabolized forms of collagen in the young rat. J. biol. Chem. 1961, 236, 1399.

7. Stetten, M. R. Some aspects of the metabolism of hydroxyproline, studied with the aid of isotopic nitrogen. J. biol. Chem. 1949, 181, 31.

8. Prockop, D. J., B. Peterkofsky, and S. Udenfriend. Studies on the intracellular localization of collagen synthesis in the intact chick embryo. J. biol. Chem. 1962, 237, 1581.

9. Gross, J. Studies on the formation of collagen. I. Properties and fractionation of neutral salt extracts of normal guinea pig connective tissue. J. exp. Med. 1958, 107, 247.

10. Prockop, D. J., and S. Udenfriend. A specific method for the analysis of hydroxyproline in tissues and urine. Analyt. Biochem. 1960, 1, 228.

11. Prockop, D. J., S. Udenfriend, and S. Lindstedt. A simple technique for measuring the specific activity of labeled hydroxyproline in biological materials. J. biol. Chem. 1961, 236, 1395.

12. Hamilton, P. B., and P. J. Ortiz. Proline and hydroxyproline: determination of the sum of their $\alpha$-nitrogen. J. biol. Chem. 1950, 187, 733.
13. Jackson, D. S., A. A. Leach, and S. Jacobs. The amino acid composition of the collagen fractions of rabbit skin. Biochem. biophys. Acta (Amst.) 1958, 27, 418.

14. Thompson, R. C., and J. E. Ballou. Studies of metabolic turnover with tritium as a tracer. V. The predominantly non-dynamic state of body constituents in the rat. J. biol. Chem. 1956, 223, 795.

15. Jackson, D. S., and J. P. Bentley. On the significance of extractable collagens. J. biophys. biochem. Cytol. 1960, 7, 37.

16. Ziff, M., A. Kibrick, E. Dresner, and H. J. Gribetz. Excretion of hydroxyproline in patients with rheumatic and non-rheumatic diseases. J. clin. Invest. 1956, 35, 579.

17. Prockop, D. J., and A. Sjoerdsma. Significance of urinary hydroxyproline in man. J. clin. Invest. 1961, 40, 843.

18. Kibrick, A. C., C. Q. Hashiro, and L. B. Safier. Hydroxyproline peptides of urine in arthritic patients and controls on a collagen-free diet. Proc. Soc. exp. Biol. (N. Y.) 1962, 109, 473.

19. Meilman, E., M. M. Urivetzky, and C. M. Rapoport. Urinary hydroxyproline peptides. J. clin. Invest. 1963, 42, 40.

20. Sjoerdsma, A., J. D. Davidson, S. Udenfriend, and C. Mitoma. Increased excretion of hydroxyproline in Marfan's syndrome. Lancet 1958, $2,994$.

21. Martin, G. R., S. E. Mergenhagen, and D. J. Prockop. Influence of scurvy and lathyrism (odoratism) on hydroxyproline excretion. $\mathrm{Na}$ ture (Lond.) 1961, 191, 1008.

22. Jasin, H. E., C. W. Fink, W. Wise, and M. Ziff. Relationship between urinary hydroxyproline and growth. J. clin. Invest. 1962, 41, 1928.

23. Dull, T. A., L. Causing, and P. H. Henneman. Urinary total hydroxyproline as an index of connective tissue turnover in bone (abstract). J. clin. Invest. 1962, 41, 1355.

24. Keiser, H. R., and A. Sjoerdsma. Effect of thyroid hormone on collagen metabolism (abstract). J. clin. Invest. 1962, 41, 1371.

25. Rodnan, G. P., and R. J. Cammarata. Urinary excretion of hydroxyproline in progressive systemic sclerosis (diffuse scleroderma). Clin. Res. 1963, $11,179$.

26. Woessner, J. F. Catabolism of collagen and noncollagen protein in the rat uterus during postpartum involution. Biochem. J. 1962, 33, 304. 